\title{
Approaching the Non-Linear Shannon Limit
}

\author{
Andrew D. Ellis, Jian Zhao, Member, IEEE, David Cotter
}

\begin{abstract}
We review the recent progress of information theory in optical communications, and describe the current experimental results and associated advances in various individual technologies which increase the information capacity. We confirm the widely held belief that the reported capacities are approaching the fundamental limits imposed by signal-to-noise ratio and the distributed non-linearity of conventional optical fibres, resulting in the reduction in the growth rate of communication capacity. We also discuss the techniques which are promising to increase and/or approach the information capacity limit.
\end{abstract}

Index Terms-Information rates, Modulation coding, Nonlinear optics, Wavelength division multiplexing.

\section{INTRODUCTION}

$\mathrm{T}_{\mathrm{e}}^{\mathrm{H}}$ HE capacity of optical communication links has grown exponentially since their introduction in the late 1970s, and each generation has enabled new methods of communication and services ranging from simple text e-mails through to the ubiquitous video applications in use today. This continuing growth has been enabled by many individual technological advances, including third-window distributedfeedback lasers, erbium-doped fibre amplifiers, wavelength division multiplexing (WDM), dispersion management, forward error correction and Raman amplification. Throughout this technological evolution, one constant factor has been the use of single mode optical fibre, although with evolving designs to control chromatic dispersion and non-linearity. However, there is now a growing realisation that the continuing bandwidth demand will shortly push the required capacity close to the maximum capacity which has been predicted theoretically for such fibres. The economic and other consequences of demand exceeding capacity are a matter of much debate. However, it is generally acknowledged that the current network architectures and transmission technologies will not be capable of meeting the customer bandwidth demand in the medium term. The time at which demand exceeds supply may be delayed by changes in network architecture and service pricing, but is likely to occur within

Manuscript received May 18, 2009. This material is based upon work supported by Science Foundation Ireland under Grant 06/IN/I969, Enterprise Ireland under grant number CFTD/08/333 and the European Commission project PHASORS (FP7-ICT-2007-2 22457).

The authors are with the Tyndall National Institute and Department of Physics, University College Cork, Ireland (phone: +353-21-490-4858; fax: +353-21-490-4880; e-mail: andrew.ellis@tyndalll.ie).

Copyright (c) 2009 IEEE. the next decade.

In this paper, we will review the limits to the information capacity in optical fibre communications, and investigate the modern technologies currently being researched to approach this limit. We will also outline the fundamental issues required to increase the limits of current optical networks imposed by signal-to-noise ratio and fibre non-linearities. The paper is organised as follows. In section II, we briefly review historical trends in communication bandwidth provision, before considering in section III the classical theoretical predictions of the limits to communication capacity of linear transmission channels. In section IV, the more recent development of the use of information theory to predict the capacity of non-linear channels in optical fibre communications is reviewed. Then in section $\mathrm{V}$ we describe recently proposed technologies including the multi-carrier transmission techniques of orthogonal frequency division multiplexing (OFDM) and coherent WDM, and discuss the potential of these technologies to allow significant increases in the maximum capacity of an installed optical fibre network.

\section{BACKGROUND}

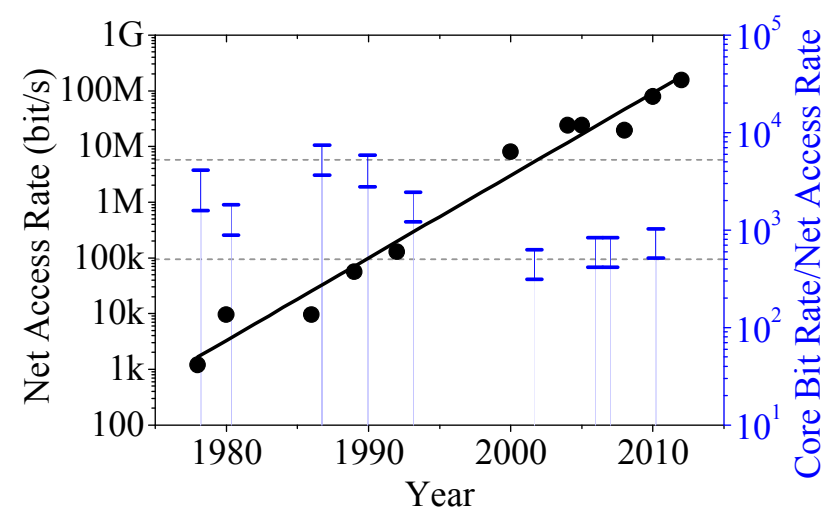

Fig. 1. Evolution of telecommunication network capacities in response to changing access technologies and consumer applications. Circles: Bandwidth of available access network connection. Candlesticks: Ratio of maximum capacity of managed link in core network to access rate. Solid line: Growth trend for net access rate, Dashed Lines: Approximate bounds of ratio of core to access capacity

The evolution of demand in telecommunications networks may be traced by plotting the bandwidth available to the user (net access rate, circles) against the date of introduction of various access technologies, as shown in figure 1, starting from the introduction of the $1.2 \mathrm{~kb} / \mathrm{s}$ modem for use in Bulletin Board Systems in 1978 [1] through to Passive Optical Networks at contended bit rates up to $10 \mathrm{~Gb} / \mathrm{s}$ [2] for video and gaming 
applications. The solid line shows a steady growth rate of $15 \%$ per annum in net access rate. To date overall network capacities, such as transatlantic link capacities, have increased at a faster rate [3] due to increasing numbers of users with access to advanced communications services.

Accompanying the increase in available access rates has been a steady increase in the bandwidth within the core of the network. The candlestick symbols in figure 1 illustrate as a function of time the ratio of two parameters: the numerator is the maximum capacity in the core network which may be independently configured (for example, a T1 or T2 carrier in 1978 , and a $40 \mathrm{~Gb} / \mathrm{s}$ SONET wavelength or $100 \mathrm{GbE}$ wavelength in 2012); and the denominator is the available access rate. Despite the exponential growth in bandwidth demand, this ratio has remained remarkably constant, representing the continual design trade off that is made between, on one hand, complexity (favouring coarse bandwidth granularity in the core network), and on the other hand, reliability (favouring fine granularity). Over a period of three decades since the late 1970s to the present day, these ratios have consistently fallen within a band of values 500 5,000 (horizontal dashed lines, figure 1). Despite profound developments in the underlying technologies over this period, it would appear that the basic cost-driven design trade-offs have remained unchanged. Therefore, extrapolating these bands of values into the future suggests that the network should be able to support $100 \mathrm{~Gb} / \mathrm{s}$ transport in the core network today [4] and $1 \mathrm{~Tb} / \mathrm{s}$ transport as early as 2017 . However, to maintain the current core network architecture, this would require a total number of wavelengths deployed similar to today, typically 160 , but carrying information at an information spectral density exceeding $30 \mathrm{~b} / \mathrm{s} / \mathrm{Hz}$ (which represents an immense technical challenge).

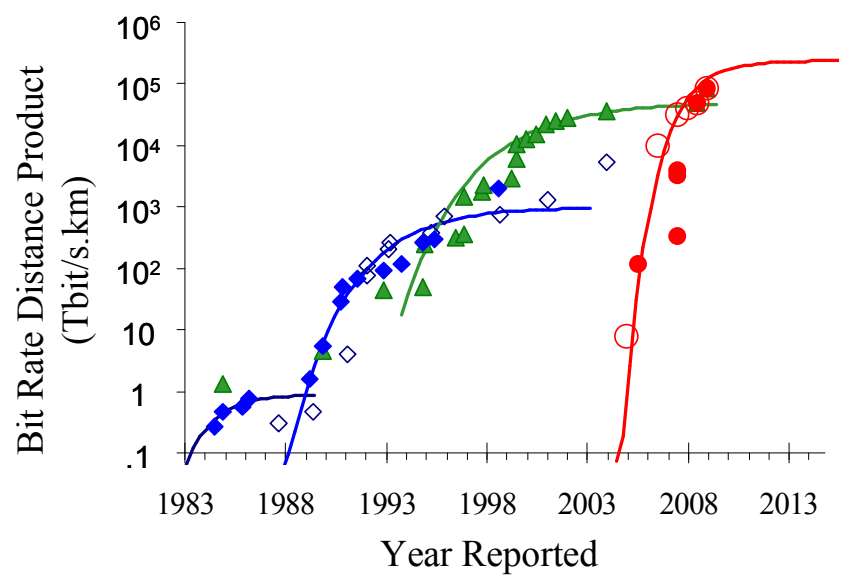

Fig. 2. Evolution of maximum reported transmission capacity for single wavelength (diamonds, open symbols for optical time division multiplexing), wavelength division multiplexing (triangles), single and multi-banded OFDM (filled circles) and coherent detection (open circles).

On the other hand, figure 2 illustrates the evolution of the available fibre transmission capacity reported from experiments carried out in research laboratories worldwide. Whilst a long term growth trend of around $60 \%$ per annum was observed from the early 1990s, this has saturated recently, prompting a move towards the adoption of coherent detection techniques, where the additional degree of freedom (optical phase) is expected to allow for greater capacity increases [5]. However, even with such innovations, capacity increases of about 25 times the current capacity, as required around 2017, appear to be very challenging.

\section{SHANNON LIMIT}

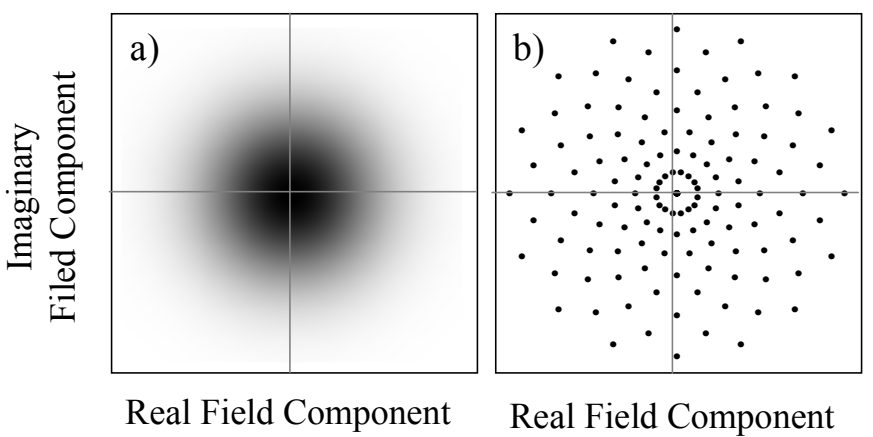

Fig. 3. a) Ideal transmitted constellation (continuous) and b) discrete point approximation (after [8]).

The Shannon limit to information capacity on a communications link $[6,7]$ is well known. Shannon proved that reliable communication over a discrete memory-less channel is possible if the communication rate $R$ satisfies $R<C$, where $C$ is the channel capacity, and is given by

$$
C=B \log _{2}\left(1+\frac{P_{a v e}}{N_{0} B}\right)
$$

where $P_{\text {ave }}$ is the average signal power and equals $C \cdot E_{\mathrm{b}}$, where $E_{\mathrm{b}}$ is the average energy per bit, $N_{0}$ the noise spectral density and $B$ the channel bandwidth. The proof presented in [6] assumes arbitrary line and error correction coding. For a linear channel degraded by additive white Gaussian noise, the optimum constellation in phase and quadrature components of the optical field may be calculated. The optimum field takes arbitrary continuous values, with the probability of each value following a Gaussian distribution [5]. Such a continuous biGaussian distribution may be emulated in practice by a discrete-point constellation $[8,9]$, as shown in figure 3 . In a well designed discrete point constellation the density of points reduces with distance from the centre of the constellation, in a manner approaching the optimum distribution. This approximation may be improved further by varying the probability of occupancy of each point in the constellation.

Many different constellations may be considered for optical transmission (as shown for example in figure 4), ranging from single quadrature formats typically generated with a single amplitude modulator, including (a) binary phase shift keying (BPSK), (b) amplitude shift keying (ASK) and (c) quaternary ASK (4-ASK), to formats consisting of in-phase and quadrature components, including ( $\mathrm{d}$ and e) M-ary phase shift keying (QPSK and 8PSK respectively), (g and $\mathrm{h}$ ) quadrature amplitude shift keying (QAM) constellations (typically 
generated using a dual parallel Mach Zehnder modulator), and (f) hybrid amplitude phase shift keying (APSK) (typically generated using an amplitude modulator and a phase modulator in series).

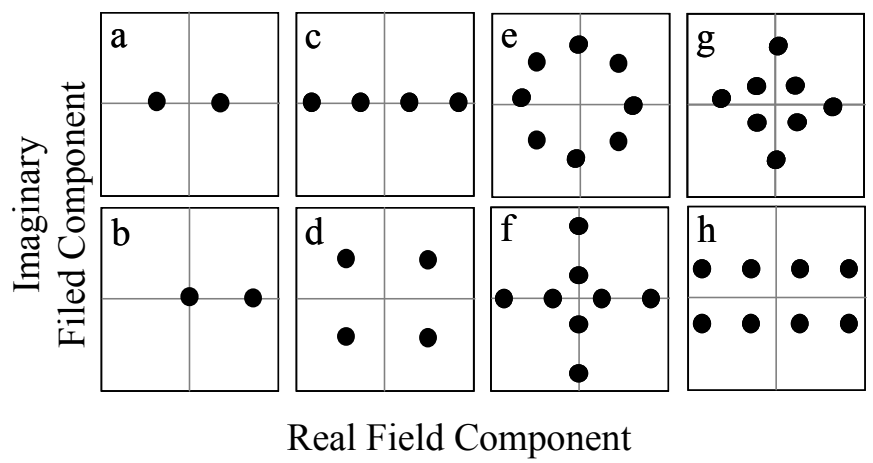

Fig. 4. Some examples of signal constellations with one $(a, b)$, two $(c, d)$ and three (e-h) bits per symbol.

To calculate the performance of each constellation, we first determine the impact of noise on each constellation point. For a system using coherent detection, the noise and signal are combined as a vector addition and the noise is independent of the signal amplitude $[10,11]$. On the other hand, for direct- and differentially- detected signals, the noise level after detection is dependent on the signal intensity [12]. In this paper, we consider only coherent detection with signal independent noise, which is the optimum case appropriate to evaluate the performance limit. In the following, we calculate the bit error rate (BER) performance of a given constellation assuming hard decision detection, by calculating the probability that a given transmitted bit crosses an imaginary boundary (the decision threshold) between it and its nearest neighbour [13]. We use the constellation of figure $4 \mathrm{c}$ as an example.

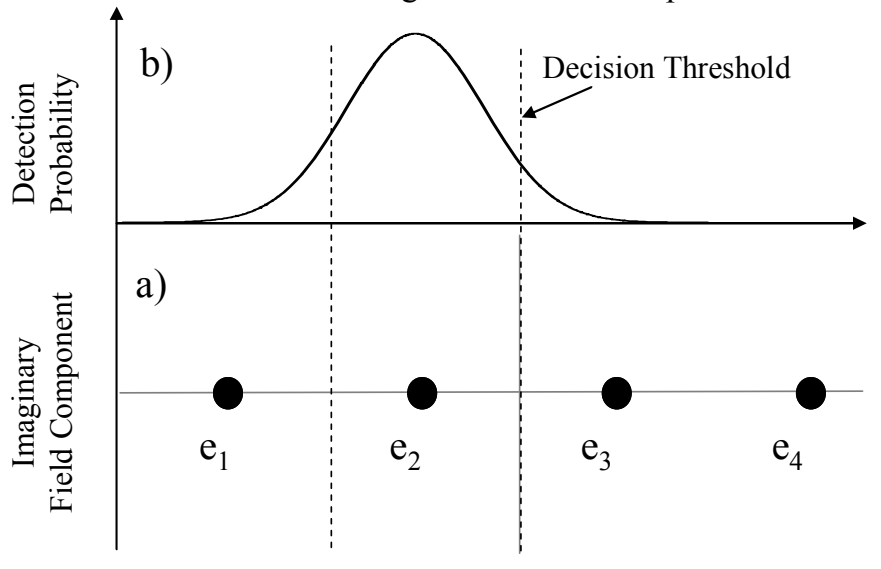

Real Field Component

Fig. 5. An example of BER calculation. a) Constellation diagram for 4-ASK, b) Probability of detecting a given field amplitude given that symbol 2 was transmitted.

In this example, also shown in figure 5, additive white Gaussian noise gives a Gaussian probability density function for the received signal values (figure $5 \mathrm{~b}$ ). For the second bit $\left(e_{2}\right)$, erroneous detection occurs by crossing either of two decision thresholds towards its nearest neighbours $\left(e_{1}\right.$ and $\left.e_{3}\right)$.
The probability of an error for this bit is thus:

$$
\left\langle\xi_{2}\right\rangle=Q\left(\frac{\left|e_{2}-e_{1}\right|}{\sqrt{2 N_{0}}}\right)+Q\left(\frac{\left|e_{2}-e_{3}\right|}{\sqrt{2 N_{0}}}\right)
$$

where $e_{i}$ is the field amplitude of the $i^{\text {th }}$ constellation point and $Q$ is related to the complimentary error function by

$$
Q(x)=\frac{1}{2} \operatorname{erfc}\left(\frac{x}{\sqrt{2}}\right)
$$

Note that here, Q represents a mathematical function, and should not be confused with the "Q-factor" used in optical communications. Note that the constellation points located at the two ends (furthest from the centre in the general case) have fewer nearest neighbours and therefore smaller error probabilities. For example, a transmitted $e_{l}$ would only be erroneously detected if it crossed the threshold between itself and $e_{2}$.

The total BER is then given by the sum of the BER for each bit $\left\langle\xi_{i}\right\rangle$ multiplied by the probability $P_{i}$ that this bit is transmitted, that is

$$
B E R=\sum_{i} P_{i} \cdot\left\langle\xi_{i}\right\rangle
$$

The transmitted signal power is related to the geometric distribution of the constellation points, such that the mean energy per bit of the transmitted bit $E_{b}$ is:

$$
E_{b}=\sum P_{i} \cdot\left|e_{i}\right|^{2}
$$

which in turn gives an electrical signal-to-noise ratio of $E_{b} / N_{0}$. Here, the signal-to-noise ratio is the parameter commonly used in communication theory, and in an optical system limited by amplified spontaneous emission noise (ASE), represents the photon number per bit entering the optical pre-amplifier. For a coherently detected signal, the electrical signal-to-noise ratio $(s n r)$ is related to optical signal-to-noise ratio (OSNR) by $\mathrm{OSNR}=R \cdot \operatorname{snr} /\left(2 B_{\text {ref }}\right)$, where $R$ and $B_{\text {ref }}$ are the transmission capacity and reference noise bandwidth (e.g. $12.5 \mathrm{GHz}$, corresponding to $0.1 \mathrm{~nm}$ at $1550 \mathrm{~nm}$ wavelength) respectively, and the ASE noise is assumed to be randomly polarised. BER performance results for a few common modulation formats are shown in table I $[11,14]$, where $m$ represents the number of constellation points $\left(\log _{2}(m)\right.$ bits per symbol) assuming $P_{i}=1 / \mathrm{m}$.

The performance of each format may then be compared to the Shannon capacity limit by calculating the required $s n r$ for a given BER and error correction code, and calculating the net information spectral density (number of transmitted bits per hertz), taking the symbol rate and the number of bits per symbol into account. 
Table I. Error probabilities for a few common modulation formats as a function of electrical signal-to-noise ratio.

\begin{tabular}{|l|c|}
\hline Format & Bit Error Probability \\
\hline $\begin{array}{l}\text { ASK } \\
\text { (figure 4b) }\end{array}$ & $Q(\sqrt{s n r})$ \\
\hline $\begin{array}{l}\text { Bi-polar MASK } \\
\text { (figure 4a\&c) }\end{array}$ & $2 \frac{m-1}{m \cdot \log _{2}(m)} Q\left(\sqrt{\frac{6 \cdot \log _{2}(m)}{m^{2}-1} s n r}\right)$ \\
\hline $\begin{array}{l}\text { BPSK } \\
\text { (figure 4a) }\end{array}$ & $Q(\sqrt{2 s n r})$ \\
\hline $\begin{array}{l}\text { MPSK (m>4) } \\
\text { (figure 4e) }\end{array}$ & $\frac{2}{\log _{2}(m)} Q\left(\sqrt{2 s n r \cdot \log _{2}(m)} \sin \left(\frac{\pi}{m}\right)\right)$ \\
\hline $\begin{array}{l}\text { Rectangular QAM } \\
\left(\begin{array}{l}\left.\log _{2}(m)=e \text { even }\right) \\
\text { (figure 4d) }\end{array}\right.\end{array}$ & $\frac{4}{\log _{2}(m)}\left(1-\frac{1}{\sqrt{m}}\right) Q\left(\sqrt{\frac{3 \log _{2}(m)}{m-1} s n r}\right)$ \\
\hline
\end{tabular}

Due to the current limitation in the electronic bandwidth, it is impractical to modulate the full optical bandwidth available. Current technologies to achieve the maximum possible information throughput involve WDM where the available optical bandwidth is split into frequency bands, each of which is modulated separately. In this case, the information spectral density $C / B$ also depends on the combined width of the guard bands between WDM channels. Figure 6 shows the information spectral density (ISD) as a function of $s n r$ in a WDM system with $20 \%$ guard bands for uni-polar ASK (circles), PSK (squares), and QAM (diamonds) formats.

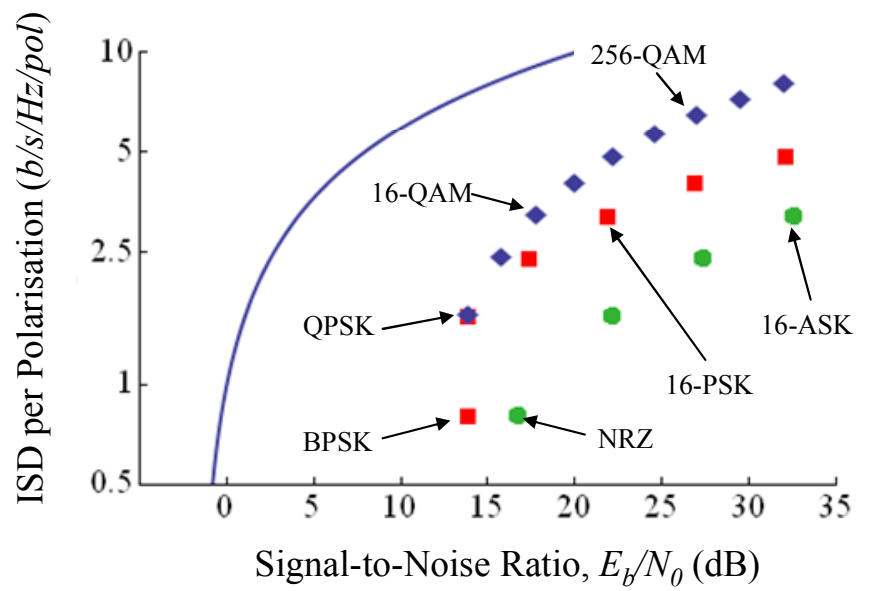

Fig. 6. Information spectral density of uni-polar ASK (circles), PSK (squares) and QAM (diamonds) showing the maximum system capacity as a function of electrical signal-to-noise ratio for a BER of $10^{-12}$ in a WDM system with $20 \%$ guard bands between channels. The solid line represents the Shannon theoretical limit $[3,6]$.

Whilst the benefits associated with modulation in both quadratures, using either M-PSK or QAM, are apparent from figure 6 and the expressions in table I and recent record spectral density results [15] strong forward error correction (FEC) is essential to enable operation close to the fundamental Shannon limit [16]. Furthermore, the use of higher order modulation formats suggests that the capacity increase is only obtained at the expense of requiring higher snr and implementation complexity. These requirements could be reduced somewhat by combining functions traditionally performed separately, for example, it has been demonstrated that demodulation and error correction may be performed simultaneously, with some performance benefit [17].

The reduction in ISD due to the FEC overhead is shown in figure 7 for various modulation formats employing coherent detection. In this figure it is assumed that the baseline system was designed to give a BER of $10^{-12}$ at a $15.5 \mathrm{~dB} \operatorname{snr}$ (sufficient for direct detection of an on-off keyed signal). The required FEC overhead for error-free operation is calculated and then subtracted from the net information capacity. A simplified approximation was used to calculate the FEC overhead, where each FEC was assumed to require 7\% overhead [18] for every $10^{-3}$ of BER to be corrected. For example, we assumed an overhead of $21 \%$ for the correction of a BER of $3 \cdot 10^{-3}$. From figure 7 , it is shown that the calculated overhead results in a negligible decrease in capacity for 2-bit per symbol uni-polar signal with coherent detection. However, as the number of bits per symbol is increased, the BER degradation increases, requiring larger overheads, and, eventually, the required additional FEC overhead outstrips the additional capacity offered by an extra bit per symbol, at a fixed snr. By changing to bi-polar, the required snr is greatly reduced, allowing, in this example, 3 bits per symbol. Exploiting both quadratures with M-PSK further reduces the required $s n r$ (see figure 6) and 4 bit per symbol M-PSK is possible at $15.5 \mathrm{~dB} s n r$ with appropriate FEC. QAM exhibits still further performance enhancement, resulting in 5 bits per symbol without significant reduction in throughput due to FEC overhead.

Whilst it is likely that FEC circuits will become available which will require less overhead than assumed here, including current proprietary FEC circuits, it will still be the case that an optimum ISD will exist for a given $s n r$ and modulation format.

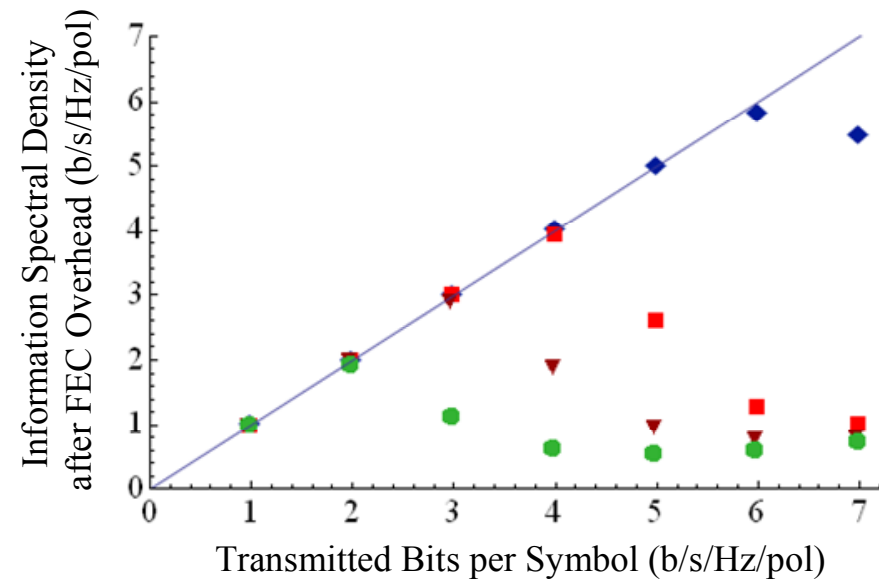

Fig. 7. Illustration of the limitation in the net information capacity as a function of the number of transmitted bit per symbols for uni-polar M-ASK (circles), bi-polar M-ASK (down triangles), M-PSK (squares) and QAM (diamonds) assuming a snr of $15.5 \mathrm{~dB}$.

It is clear that any required guard band between WDM 
channels reduces the ISD. The guard bands may be avoided by employing orthogonal frequency division multiplexing (OFDM) techniques [19,20], such as no-guard-interval OFDM [21-23], coherent WDM [24-27] direct detection OFDM $[28,29]$ and coherent optical OFDM [30-35].

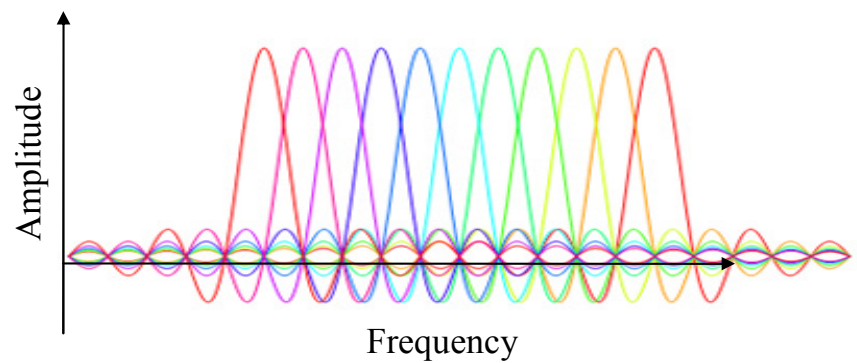

Fig. 8. Illustration of overlapping modulation sidebands of OFDM signal.

In all of these multi-carrier systems, the frequency spacing between the orthogonal sub-carriers is equal to the symbol rate per subcarrier. A typical example of the orthogonal carriers are shown in figure 8 , where the peak of the spectrum of a given channel corresponds to nulls in the spectra of all of the other sub-channels, and in particular, the first null in the spectrum of the adjacent sub-channel. Ideally, matched filters are used to separate each sub channel [19], and this may be implemented efficiently using Fast Fourier Transform algorithms for low sub-channel data rates (e.g. $100 \mathrm{Mb} / \mathrm{s}$ ), with the digital signal processing (DSP) complexity scaling approximately linearly with the total capacity $(\propto N \cdot \log N$, where $N$ is the channel number) [28-33]. However, for a system with a high symbol rate per channel (e.g. $40 \mathrm{~Gb} / \mathrm{s}$ ), the practical implementation of precise matched filters proves difficult, and may be approximated in the optical domain using asymmetric Mach Zehnder interferometers $[23,24]$ or with simple digital filters [22]. The impact of any residual crosstalk may then be minimised using appropriate optimisation of the relative phases of each sub-channel [25] or cancelled using postdetection signal processing $[26,36]$. In all cases, the net result is the straightforward generation of a signal with a capacity per polarisation equal to the number of bits per symbol (or $\left.\log _{2}(m)\right)$, with the potential suitability for ultra-high total capacities (between 300 and 1,080 Gb/s and beyond [37-39]) which are difficult to achieve using single carrier modulation.

\section{NON-LINEAR LIMITS}

The above discussion applies equally to optical fibre, wireless and copper based transmission systems, and in the absence of any further signal degradation, performance approaching the Shannon limit would be possible using forward error correction. Wireless systems, particularly those employing OFDM, experience non-linearity due to the saturation characteristics of power amplifiers [40]. On the other hand, periodically-amplified optical fibre based systems are characterised by distributed non-linear effects in the fibre itself. The most predominant non-linear effect arises from the intensity dependent refractive index (Kerr effect) and results in a number of phenomena such as self-phase modulation [41], cross-phase modulation [42] and inter- [43] and intra-channel [44] four wave mixing. Whilst many techniques to mitigate the impact of non-linearity have been developed, including most significantly dispersion management [45-49], the impact of these non-linearities in terms of the information theoretical limits have only recently been addressed [50-52]. The key simplification introduced by Mitra and Stark [50] was to equate a non-linear communication channel to a linear channel with multiplicative noise, for which analytical results can be obtained. It was found that, in contrast to linear channels with additive noise, the capacity of a non-linear channel does not grow indefinitely with increasing signal power, but has a maximal value. This is a fundamental feature which distinguishes non-linear communication channels from linear ones. In making use of this new analytical approach, it is assumed that any deterministic effects, such as chromatic dispersion and self-phase modulation, which depend only on the channel of interest, may be fully compensated. This compensation may take the form of efficient modifications of the transmitted or received signals based on prior knowledge of the signal format itself. For example, reduction in dispersion penalties are observed using pre-chirp [53,54] or electronic dispersion compensation [55-57], whilst non-linear penalties may be lowered by reducing phase noise (or timing jitter) by modulating the received signal with a phase proportional to the received intensity [58-60]. For multi-level formats, these techniques may also be applied predicatively at the transmitter [61]. Full non-linearity compensation may be applied at the expense of complexity, either by optical phase conjugation $[62,63]$, or via emulation of back propagation using look-up tables [64].

Assuming ideal compensation of all intra-channel effects other than noise, cross-phase modulation (XPM), which causes multiplicative noise, appears to be the principal source of impairments that fundamentally limits the information capacity of an optical communication system. XPM induces random fluctuations in the target channel which are exponentially related to the intensity of the neighbouring WDM channels. It has been shown that the intensity scale for these fluctuations is given by $[50,65]$

$$
I_{X P M}=\sqrt{\frac{B \cdot D \cdot \Delta \lambda}{2 \cdot \gamma^{2} \ln \left(\frac{N_{c h}}{2}\right) L_{e f f}}}
$$

where $B, D, \Delta \lambda$ and $\gamma$ are the channel bandwidth, local dispersion, WDM channel spacing and fibre non-linear coefficient respectively. $N_{c h}$ is the number of WDM channels and $L_{\text {eff }}$ is the non-linear effective length of the system given by $N_{a}[1-\exp (-\alpha L)] / \alpha$, for a system with lumped amplifiers where $\alpha$ is the loss coefficient and $N_{a}$ is the number of amplifiers. Here we have assumed equally spaced channels of equal intensities. A related amount of information is lost from the channel of interest due to the random crosstalk induced by XPM. The net effect is to reduce the information capacity of a 
coherently detected (CD) system to

$$
\left.\frac{C}{B}\right|_{C D} \geq \log _{2}\left(1+\frac{P_{\text {ave }} e^{-\left(\frac{P_{\text {ave }}}{I_{X P M}}\right)^{2}}}{P_{n}+\left(1-e^{-\left(\frac{P_{\text {ave }}}{I_{X P M}}\right)^{2}}\right) P_{\text {ave }}}\right)
$$

where $P_{\text {ave }}$ is the average signal power per channel. $P_{\mathrm{n}}$ (for a system with discrete amplifiers) is equal to $N_{\mathrm{a}}(\mathrm{G}-1) n_{\mathrm{sp}} h v B$, where $N_{\mathrm{a}}$ is the number of fibre spans, $G$ is the amplifier gain and $n_{\text {sp }}$ is the spontaneous emission noise factor. Note that this equation is applicable to OFDM or coherent WDM techniques, and in a conventional WDM system, the capacity is reduced by a factor of $B / \Delta v$, where $\Delta v$ is the channel spacing in the frequency domain. The same approach has been employed to determine the reduction in information capacity when the dominant non-linearity is four-wave-mixing [5], where the phase condition in the fibre is different. The capacity bound is given by (7) with the non-linear intensity $I_{X P M}$ replaced by $I_{F W M}$, where

$$
\begin{gathered}
\frac{1}{I_{F W M}}=N_{A} \sum_{p, q \neq 0}^{|p+q| \frac{n_{c}-1}{2}} \frac{\gamma^{2} K_{p q}^{2}}{\alpha^{2}+\left(2 \pi \lambda^{2} D \Delta f^{2} q \cdot p / c\right)^{2}} \\
K_{p q}=\begin{array}{l}
1, p=q \\
2, p \neq q
\end{array}
\end{gathered}
$$

The general form of these predictions is confirmed by independent analysis [66]. Following the same general argument, it may be expected that the maximum ISD of a system employing direct detection (DD) is similarly degraded. Thus starting from the linear ISD limit [5, 67], we find (for high OSNR) that:

$$
\left.\frac{C}{B}\right|_{D D} \approx \frac{1}{2} \log _{2}\left(\frac{P_{a v e} e^{-\left(\frac{P_{a v e}}{I_{X P M}}\right)^{2}}}{P_{n}+\left(1-e^{-\left(\frac{P_{\text {ave }}}{I_{X P M}}\right)^{2}}\right) P_{\text {ave }}}\right)-1
$$

Figure 9 depicts the XPM-limited ISD versus transmitted power density for coherent and direct detection. The information limits in the linear channels are also plotted for comparison. In the figure, a high local dispersion coefficient value $D$ and a non-quasi-phase-matched dispersion map are assumed to avoid resonances in the non-linear response of the system [43, 47]. High local dispersion values can help to reduce the interaction between the WDM signals and ASE by minimising the phase matching. The figure shows the increase in maximum ISD achieved by using coherent detection, and the effect of fibre non-linearity at higher transmitted powers preventing indefinite growth in the channel capacity. For this particular example, the effect of XPM becomes prominent at transmitted power densities beyond $\sim 0.01 \mathrm{~W} / \mathrm{THz}$, and a maximum ISD of $6 \mathrm{~b} / \mathrm{s} / \mathrm{Hz}$ is predicted. A similar value was reported in recent numerical simulations [68].

Table II. Simulation parameters used for figure 9 onwards, unless otherwise specified. Values are selected to indicate general trends and do not represent actual system designs.

\begin{tabular}{|c|c|}
\hline Parameter & Value \\
\hline System Length & $2,000 \mathrm{~km}$ \\
\hline Amplifier Spacing & $80 \mathrm{~km}$ \\
\hline Amplifier Noise Figure & $4.5 \mathrm{~dB}$ \\
\hline Channel Spacing & $50 \mathrm{GHz}$ \\
\hline Baud Rate & $50 \mathrm{Gbaud}$ \\
\hline Fibre Loss & $0.2 \mathrm{~dB} / \mathrm{km}$ \\
\hline Non-linear coefficient & $1 \mathrm{~W}^{-1} \mathrm{~km}^{-1}$ \\
\hline $\begin{array}{c}\text { Group Velocity } \\
\text { Dispersion }\end{array}$ & $20 \mathrm{ps} / \mathrm{nm} / \mathrm{km}$ \\
\hline Wavelength & $1550 \mathrm{~nm}$ \\
\hline Amplifier Bandwidth & $5 \mathrm{THz}$ \\
\hline Number of channels & 101 \\
\hline
\end{tabular}

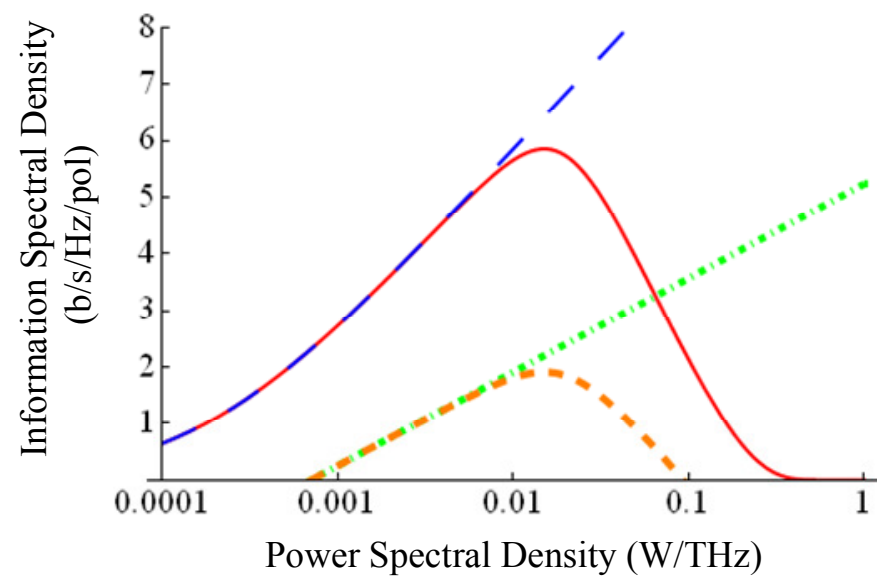

Fig. 9. Examples of predicted information spectral density limits per polarisation for linear transmission with coherent (long dashes) and direct (dot-dashed) detection and for non-linear transmission including XPM for coherent (solid) and direct (short dashes) detection. Detailed parameters are shown in table II.

It is relatively straightforward to calculate the maximum launch power from (7) above, and thus predict the maximum ISD for any given system configuration. Since the inception of optical communication systems, advances in various individual technologies have enabled these limits to be approached, and the ratio of ISDs for numerous reported transmission system experiments to the maximum values are shown in figure 10 . Much of the progress is attributed to improvements in modulation efficiency, adoption of WDM and the subsequent reduction in channel spacing. The reason for the recent reduction in the rate of growth of bit rate distance product (figure 2) also becomes apparent, as we observe in figure 10 that experimental measurements had already exceeded $50 \%$ of 
the theoretical maximum information capacity by 2008 [69]. This imminent limit to growth in the information capacity is stimulating renewed interest in techniques for mitigating the effect of non-linearity, in order to allow operation at higher launch powers, and hence higher overall capacities (figure 9).

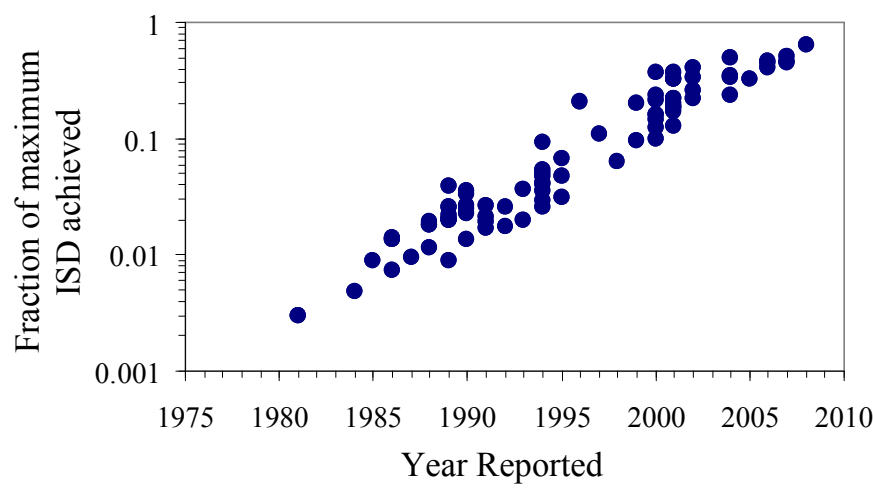

Fig. 10. Maximum reported information capacity as a fraction of the maximum information capacity (7) for the system configuration reported versus the year for transmission distances up to $2,000 \mathrm{~km}$.
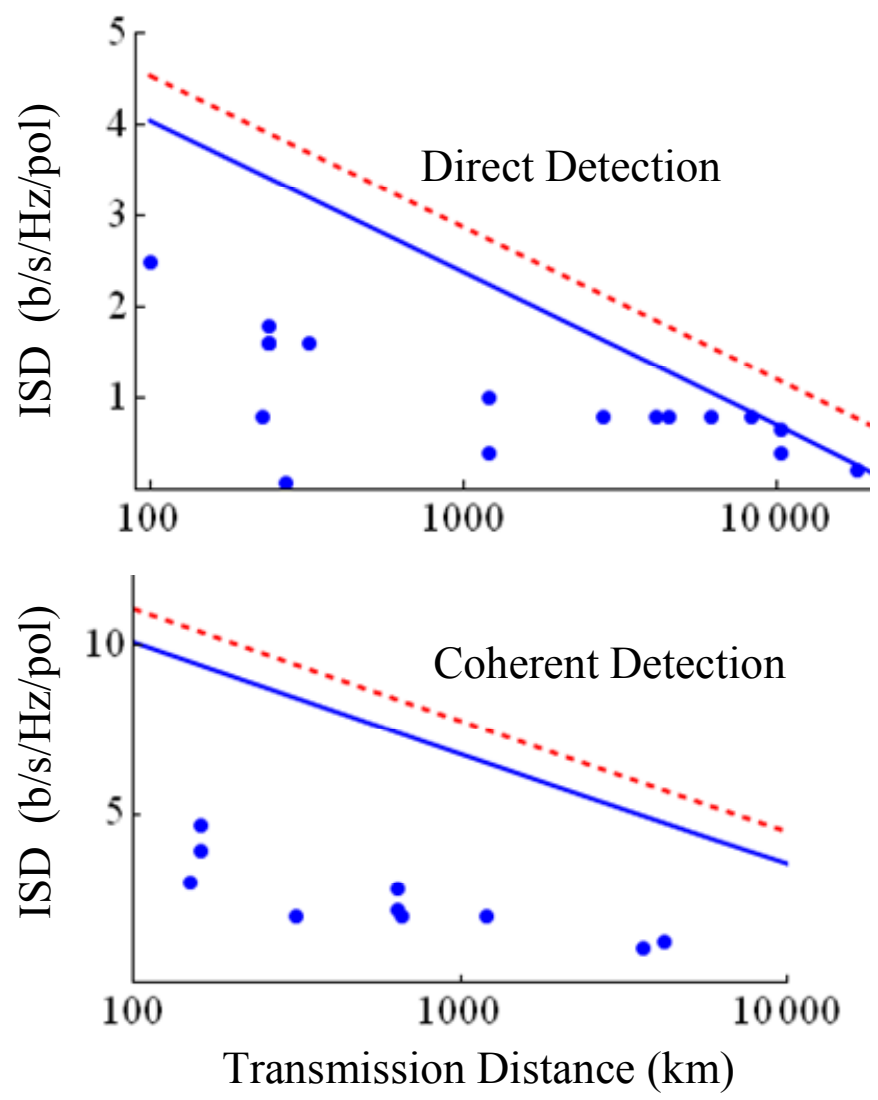

Fig. 11. Maximum reported information spectral density versus transmission distance for experimentally reported data (dots) and theoretical limits (lines) with EDFA-amplified systems with $40 \mathrm{~km}$ repeater spacing (dotted line) and $80 \mathrm{~km}$ spacing (solid line) (other parameters as per table II).

Experimental data is also compared to the theoretical limits in figure 11, but, this time, as a function of transmission distance for direct detection (upper) and coherent detection (lower). Again, we readily observe that recent experimental results are within a factor of two of the maximum ISD predicted by (7).

For the longest transoceanic systems $(>10,000 \mathrm{~km}$ and based on direct detection [60,70,71]), whilst the achieved ISDs are usually modest, below $1 \mathrm{~b} / \mathrm{s} / \mathrm{Hz}$, the results closely approach the Shannon limit. In these papers, the dispersion maps were optimised to minimize the impact of optical nonlinearity; this was achieved in various ways: by removing all dispersion compensation from the system [70]; by combining multiple fibre types within the transmission span with different properties [71] or by destroying quasi-phase matching [43,44] by carefully balancing broadband dispersion compensation (fibre based) and using a periodic group delay compensation device [60]. With the benefit of hindsight, we can say that each of the dispersion management schemes above follow the predictions of (7). In addition, these results partially benefited from a degree of non-linearity compensation, either through the use of guiding filters to combat intra-channel self-phase modulation $[60,72]$, or via mid-span spectral inversion [62, 70].

Coherent detection can greatly increase the limits to information capacity, and has attracted much interest recently for long haul transmission [33]. In order to approach the maximum information spectral density in such system, the dispersion is maintained at its maximum value throughout the transmission to minimise non-linear effects, and the information capacity of the transmitted channel may be increased by using OFDM to minimise the spacing of subcarriers, and by using QPSK modulation on each sub-carrier. Similar results were obtained using 134 WDM channels, each of which carried OFDM with QPSK sub-carriers [22]. In both cases, coherent detection not only fundamentally increased the information capacity limit by reducing the information loss from noise and allowing access to a second quadrature, but also enabled the compensation of the accumulated chromatic dispersion using DSP.

For shorter transmission distances more suited to inland networks, transmission reaches in the region of 1,000 to 1,500 $\mathrm{km}$ are required [4]. In this case, a direct detection system which also uses a form of OFDM to increase the ISD may be used [27], where a dispersion map optimised for $40 \mathrm{~Gb} / \mathrm{s}$ transmission was used to minimise the impact of non-linearity $[49,73]$. With coherent detection, fibre non-linearity was successfully managed over an in-line compensated map by using a RZ-shaped constant intensity modulation format, and the ISD was increased further using 8-PSK [74].

Over even shorter distances, the improved OSNR enables the use of yet higher-order modulation formats. Although a wide variety of formats have been studied, the highest ISDs are typically associated with single side-band [75], OFDM [35], and large constellation QAM systems $[15,76]$, the common feature of which is the efficient use of the available spectrum by minimising duplication of information. 


\section{INCREASING THE INFORMATION CAPACITY LIMIT}

We observed in section IV that, for both direct and coherent detection, the latest experimental results are falling on a line approximately a factor of two away from the ultimate limits predicted by the Shannon limit incorporating the effects of cross-phase modulation. In the few cases where this gap appears to have been closed, the experiments mitigated the fibre non-linearity $[60,70]$ or employed larger effective area fibre (note that the reference calculations assumed a fixed value of these parameters) $[71,77]$.

In addition to implementing the various modulation formats, impairment mitigation techniques, and FEC technologies to approach the limit, it is also desirable to increase the maximum information spectral density by taking optimum values for the parameters in (6-8), including critical fibre characteristics (loss, dispersion and non-linear coefficient), the channel spacing, the effective amplifier noise figure and finally the number of cascaded links. The capabilities of optically multiplexed OFDM [39], or coherent WDM [27,37] to generate phase coherent high capacity signals from a single source, suggests one way to extend the theoretical ISD limit. That is, by increasing the channel spacing, if compensation of the linear and non-linear impairments may be applied across the entire OFDM spectrum, an increased fraction of the spectrum may be treated as a single channel [78,79]. Through (7) we may expect that this would reduce the impact of XPM enabling the information capacity limit to be enhanced.

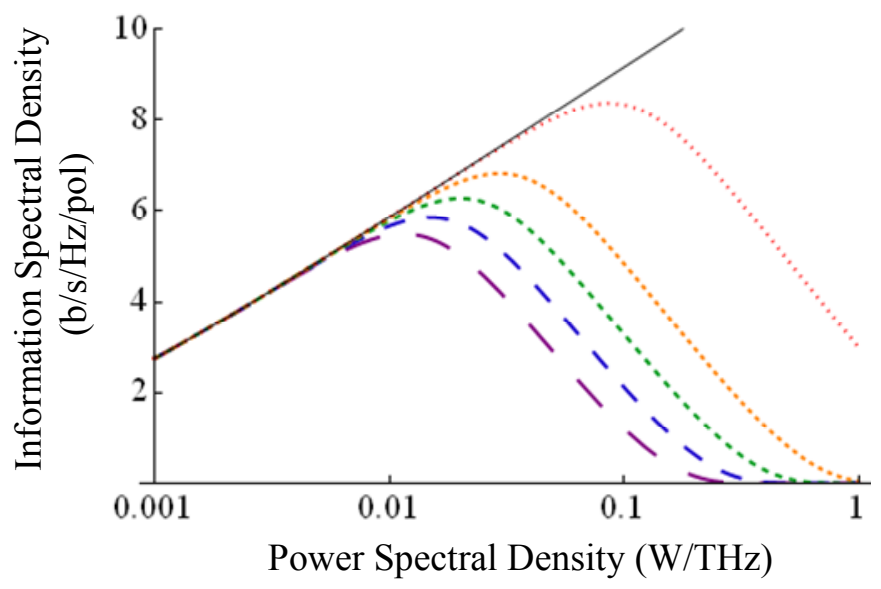

Fig. 12. Theoretical channel information spectral density limits versus power spectral density in a $10 \mathrm{THz}$ bandwidth, plotted for different values of the channel bandwidth: $1 \mathrm{GHz} 100 \mathrm{GHz}, 1 \mathrm{THz}, 3 \mathrm{THz}, 5 \mathrm{THz}$ and $10 \mathrm{THz}$ (dashing length varies from $1 \mathrm{GHz}$-longest to $5 \mathrm{THz}$ shortest, and $10 \mathrm{THz}$ is the solid line) with other parameters as per table II.

In these systems, for a fixed amplifier bandwidth, e.g. $10 \mathrm{THz}$, the non-linear ISD limit arising from XPM is dependent on the channel granularity, as shown in figure 12, which depicts the theoretical capacity limit in a $10 \mathrm{THz}$ bandwidth for different channel spacing (or occupied bandwidth per channel in OFDM systems). From this figure, it can be seen that the maximum information capacity is increased as the channel bandwidth increases due to the anticipated dependence of information capacity with channel bandwidth (6). The curve for $10 \mathrm{THz}$ corresponds to the one-channel case without the possibility of $\mathrm{XPM}$, and this is the same as the Shannon limit in a linear channel. The bandwidth per channel is typically less than 100 $\mathrm{GHz}$ in present commercially available systems; a limit imposed both by standardisation and also by the available modulation and detection bandwidths.

The logarithmic dependence of (1) and (7) with respect to the noise power spectral density reduces the benefit from amplifier noise figure reductions, as showing in figure 13 , such that a 1 $\mathrm{dB}$ reduction in noise figure results in substantially less than a $1 \mathrm{~dB}$ increase in the maximum ISD. In figure 13, we consider the effect of reducing the amplifier noise figure from a typical value of $4.5 \mathrm{~dB}$ to the quantum limit of $3 \mathrm{~dB}$, confirming that this offers only a small increase in the maximum ISD. In this example, the ISD limit may be increased by a further $1 \mathrm{~b} / \mathrm{s} / \mathrm{Hz}$ by using phase sensitive amplification for which the theoretical minimum noise figure is $0 \mathrm{~dB}$. Note that, in this case, we must consider the quantum nature of light and that the photon number distribution is fundamentally broadened by periodic attenuation and amplification. The net effect of these quantum processes is that the signal-to-noise ratio is improved by a factor of 2 by moving from a quantum-limited phase insensitive amplifier to a quantum-limited phase sensitive amplifier [12,80,81]. Similarly modest increases in capacity are expected from systems operating with distributed amplification, where the OSNR is maximised [8]. Whilst the increase in net ISD is small, of greater interest is the required total launch power for a given ISD. For an ISD of $5.85 \mathrm{~b} / \mathrm{s} / \mathrm{Hz}$, according to figure 13 , a system comprising $4.5 \mathrm{~dB}$ noise figure amplifiers would require a launched power spectral density of around $14 \mathrm{~mW} / \mathrm{THz}$. This would result in a system operating in a non-linear transmission regime, requiring proper design to minimise inter-channel non-linearity, and full compensation of intra-channel non-linearity. On the other hand, the use of ideal phase sensitive amplifiers allows the operation of the same system in a linear transmission regime, with a launch power spectral density of only $3.5 \mathrm{~mW} / \mathrm{THz}$, representing a substantial energy saving, even when the reduced power efficiency of phase sensitive amplifiers [82] is taken into account. Practical deployment of such phase sensitive amplifiers requires further development to realise fibre to fibre noise figures approaching the assumed $0 \mathrm{~dB}$, and the development of systems to ensure that the useable gain bandwidth of a phase sensitive amplifier approaches that of the phase insensitive parametric amplifiers [83] 


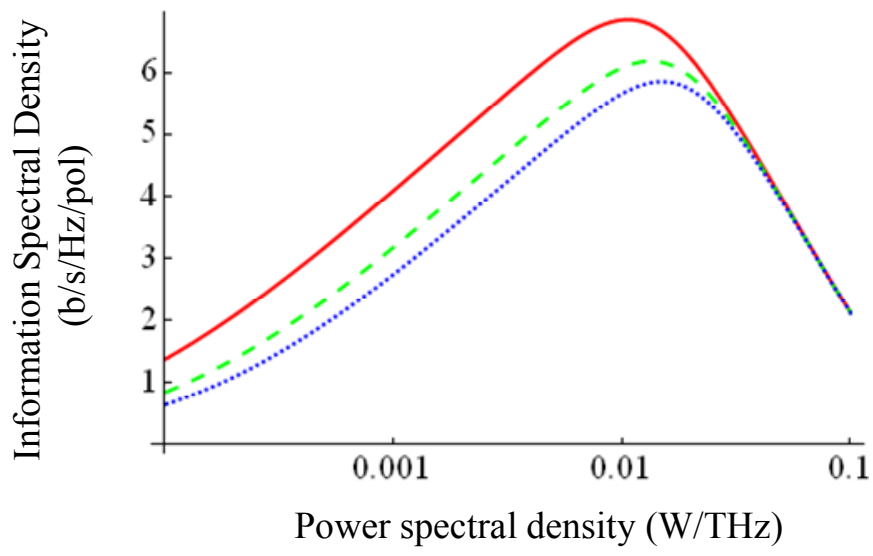

Fig. 13. Theoretical channel ISD for various values of the amplifier noise figure (dotted: $4.5 \mathrm{~dB} \mathrm{NF}$, dashed: $3 \mathrm{~dB} \mathrm{NF}$, solid: $0 \mathrm{~dB} \mathrm{NF}$ ), other parameters as per table II.

We may therefore conclude from figure 13 that the overall capacity could in principle be increased by $1-2 \mathrm{~b} / \mathrm{s} / \mathrm{Hz}$ by only modifying the transponders and amplifier sites, offering significant practical advantage.

Fibre designs, on the other hand, offers substantially greater scope for performance improvement. Indeed many transmission records were attributed to the fibre designs $[71,84]$ in addition to optimised transmission formats. Figure 14 illustrates the predicted maximum performance for a number of measured solid core fibres, all of which demonstrate a maximum information capacity between 6 and $8 \mathrm{~b} / \mathrm{s} / \mathrm{Hz}$, assuming optimum dispersion management and full compensation of intra-channel non-linearity. Figure 14 also shows for comparison speculative prediction of the performance of a hollow core photonic crystal fibre (PCF), where the non-linear coefficient has been reduced in proportion to the estimated fraction of the optical signal propagating in glass (1\%) and the predicted minimum loss has been assumed [85]. Preliminary transmission measurements [86] have been performed at a wavelength of $1550 \mathrm{~nm}$. In this region, whilst the loss will be higher than that for conventional fibres, it might be expected that the significantly reduced nonlinearity would enable the development of a hybrid system, with PCF used in sections experiencing high optical powers, and low loss fibre elsewhere. Development of the necessary transponder and amplifier technology [e.g. 87, 88] for operation in the mid-infrared region, accompanied by achievement of the predicted low loss performance around $1900 \mathrm{~nm}$, should enable the development of long reach communication with information capacities above $10 \mathrm{~b} / \mathrm{s} / \mathrm{Hz}$. The overall capacity of the fibre will of course be restricted by the wavelength range over which the fibre wave-guiding is effective. Reductions in the effective non-linear coefficient are also expected for multi-mode fibre systems [89], and proportional increases in maximum ISD may be expected if appropriate measures are taken to accommodate the bandwidth limitations.
Table III. Fibre parameters used for figure 14 (Est: Estimated from effective area or fraction of light propagating in medium, *: assumed value for chromatic dispersion, \$: predicted value)

\begin{tabular}{|c|c|c|c|c|}
\hline Fibre Type & $\begin{array}{c}\text { Loss } \\
(\mathrm{dB} / \mathrm{k} \\
\mathrm{m})\end{array}$ & $\begin{array}{c}\text { Non-linear } \\
\text { coefficient } \\
\left(\mathrm{W}^{-1} \mathrm{~km}^{-1}\right)\end{array}$ & $\begin{array}{c}\text { Wave- } \\
\text { band } \\
(\mathrm{nm})\end{array}$ & $\begin{array}{c}\text { Dispersion } \\
(\mathrm{ps} / \mathrm{nm} / \mathrm{km})\end{array}$ \\
\hline $\begin{array}{c}\text { SMF-28 } \\
\text { Large area SMF } \\
{[71]}\end{array}$ & 0.2 & 1 & 1550 & 17 \\
\hline $\begin{array}{c}\text { LongLine } \\
{[90]}\end{array}$ & 0.23 & $0.85^{\text {Est }}$ & 1550 & $17^{*}$ \\
\hline $\begin{array}{c}\text { Ultrawave } \\
{[91]}\end{array}$ & 0.185 & $0.75^{\text {Est }}$ & 1550 & $17^{*}$ \\
\hline $\begin{array}{c}\text { Vascade } \\
\text { EX1000 }\end{array}{ }^{\mathrm{TM}}[92]$ & 0.175 & $1.15^{\text {Est }}$ & 1550 & 18.5 \\
\hline $\begin{array}{c}\text { Hollow Core } \\
\text { PCF [85] }\end{array}$ & $0.13^{\text {\$ }}$ & $0.01^{\text {Est }}$ & 1900 & $17^{*}$ \\
\hline
\end{tabular}

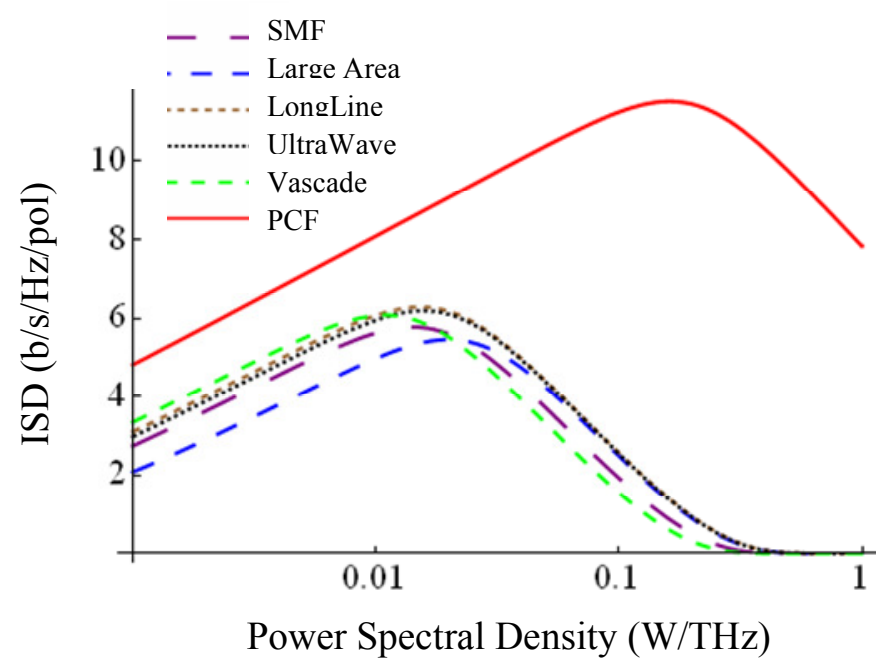

Fig. 14. Maximum ISD of various fibre types. See table III for fibre parameters and table II for other parameters.

\section{CONCLUSIONS}

Communication capacity has shown a remarkable exponential growth over more than 30 years, with the overall capacity of the core of the network closely tracking the user demand. In this paper we have discussed the recent reduction in the growth rate of communication capacity in laboratory systems and have shown that this is because the reported capacities are approaching the fundamental limits imposed by signal-to-noise ratio [6] and the distributed non-linearity of conventional optical fibres [50].

In the short term, capacity growth by a factor of approximately two may be expected by each of the following approaches: compensation of intra-channel non-linearity either through link design or signal processing at the terminals; increase in the total bandwidth (and capacity) of each channel using phase coherent optical multiplexing; optimisation of the OSNR through careful link design; adoption of distributed and phase sensitive amplifiers and optimisation of the amplifier spacing. However, with the underlying long term rate of capacity 
growth equal to a doubling every two years, it appears inevitable that unless capacity demand saturates, or network architectures are devised which radically alter the capacity demands placed on the core network, new transmission media will be essential within the next two decades.

\section{ACKNOWLEDGMENT}

The authors would like to thank Dr S. Ibrahim for useful discussions.

Dr. Andrew Ellis was born in Underwood, England in 1965 and gained a BSc in Physics with a minor in mathematics from the University of Sussex, Brighton, England in 1987. He was awarded his $\mathrm{PhD}$ in Electronic and Electrical Engineering from The University of Aston in Birmingham, Birmingham, England in 1997 for his study on All Optical Networking Beyond $10 \mathrm{Gbit} / \mathrm{s}$.

He previously worked for British Telecom Research Laboratories as a Senior Research Engineer investigating the use of optical amplifiers and advanced modulation formats in optical networks and the Corning Research Centre as a Senior Research Fellow where he led activities in optical component characterisation. Currently, he heads the Transmission and Sensors Group at the Tyndall National Institute in Cork, Ireland, where he is also a member of the Department of Physics, University College Cork. He research interests include the evolution of core and metro networks, and the application of photonics to sensing.

Dr Ellis is a member of the Institute of Physics and the Institute of Engineering Technology, and is a Chartered Physicist. He acts as a reviewer for IEEE Journal of Lightwave Technology and Photonics Technology Letters and has published over 100 journal papers and over 20 patents in the field of Photonics.

Dr Jian Zhao received a B.Eng degree from University of Science and Technology of China (USTC) in 2002, M.Phil. and Ph.D. degrees from the Chinese University of Hong Kong (CUHK) in 2004 and 2007 respectively. During 2002-2004, he worked on supercontinuum-based photonic devices for multi-wavelength optical networks. In his Ph.D. program (2004-2007), his research interests included electronic signal processing and advanced modulation formats in optical communication and wavelength-division multiplexing passive optical networks.

He joined the Photonic Systems Group at the Tyndall National Institute as a Postdoctoral Research Scientist in August 2007. His current research interests include electronic signal processing in optical communications and spectrally-efficient multi-carrier optical transmission systems.

Dr Zhao is the member of IEEE and is an Enterprise Ireland principal investigator. He was the recipient of the First Prize of Outstanding Student Scholarship of USTC. He has published more than 30 technical papers in peer-reviewed international journals and conferences and 1 patent

Prof David Cotter graduated from Southampton University, Southampton, U.K., and received the Ph.D. degree in non-linear optics in 1976. He was awarded a D.Sc. degree by Southampton University in 1996 for contributions to the field of non-linear optics and its applications in quantum electronics, semiconductor physics and telecommunications.

He heads the Photonic Systems Group at the Tyndall National Institute in Cork, Ireland, where he is also a member of the Department of Physics, University College Cork. Formerly, he was with Corning Research Centre, Ipswich, U.K., British Telecom Research Laboratories in Ipswich, U.K., the Max-Planck Institute for Biophysical Chemistry in Goettingen, Germany, and the Atomic Energy Research Establishment in Harwell, U.K.

Prof. Cotter is a Fellow of the Institute of Physics, a Chartered Physicist and Chartered Engineer.

\section{REFERENCES}

[1] L. Wood, D. Blankenhdn, "State of the BBS nation: Behold lowly bulletin board now encompassing the globe", Byte, January 1990, pp 298-304 (1990) and C.K.Ramaiah, "Bulletin Board Systems for Libraries", DESIDOC Bulletin of Information Technology, Vol. 15, No. 4, pp 23-31 (1995).

[2] IEEE P802.3av Task Force, "10 Gb/s Ethernet Passive Optical Network", http://www.ieee802.org/3/av, downloaded 20/4/2009.
[3] E.B. Desurvire, "Capacity Demand and Technology Challenges for Lightwave Systems in the Next Two Decades", Journal of Lightwave Technology, Vol. 24, No. 12, pp. 4697-4710 (2006)

[4] P. Magill, "System Technologies for 100G Transport Networks", Proc OFC 2009, San Diego, Paper OThR1 (2009).

[5] J.M. Kahn, K-P. Ho, "Spectral Efficiency Limits and Modulation/Detection Techniques for DWDM Systems", IEEE J. Selected Topics in Quantum Electronics, Vol.10, No.2, pp 259-272 (2004).

[6] C.E. Shannon, "A Mathematical Theory of Communication", Bell System Technical Journal, Vol.27, pp379-423, pp 623-656 (1948).

[7] C.E. Shannon, W. Weaver, The Mathematical Theory of Communication, University of Illinois Press (1963).

[8] R.-J. Essiambre, "Capacity Limits of Fiber-Optic Communication Systems", Proc OFC 2009, San Diego, ISA, Paper OThL1 (2009).

[9] N. Kikuchi, K. Mandai, K. Sekine, S. Sasaki, "Incoherent 32-Level Optical Multilevel Signalling Technoloigies", Journal of Lightwave Technologies, Vol. 26, No.1, pp 150-157, (2008).

[10] J.M.Kahn, E.Ip, "Principles of Digital Coherent Receivers for Optical Communications", Proc OFC 2009, San Diego, ISA, Paper OTuG5 (2009).

[11]E. Ip, A.P.T. Lau, D.J.F. Barros, J.M. Khan, "Coherent detection in optical fiber systems", Optics Express, Vol.16, No.2, pp. 753-791 (2008)

[12] E. Desurvire, Erbium-doped Fiber Amplifiers, Hoboken, John Wiley and Sons Inc (2002).

[13] S. Haykin, Digital Communications, Wiley (1988).

[14] J.G. Proakis, Digital Communications (4th Edition), New York, McGraw-Hill (2000)

[15] M. Nakazawa, "Challenges to FDM-QAM coherent transmission with ultrahigh spectral efficiency”, Proc ECOC 2008, Brussels,Paper Tu1E1, (2008).

[16]S.Y. Chung, G.D. Forney, T.J. Richardson, R. Urbanke, "On the Design of Low Density Parity Check Codes within $0.0045 \mathrm{~dB}$ of the Shannon Limit", IEEE Communications Letters, Vol.5, No.2, pp58-60 (2001).

[17] B. Zhou, L. Zhang, J. Kang, O. Huang, Y.Y. Tai, S. Lin, M. Xu, “ Nonbinary LDPC codes vs. Reed-Solomon codes", Proc Information Theory and Applications Workshop 2008, San Diego, pp175-184 (2008).

[18] G.709: Interfaces for the Optical Transport Network (OTN), downloaded from http://www.itu.int/rec/T-REC-G.709/en.

[19] R.W. Chang, "Synthesis of band-limited orthogonal signals for multichannel data transmission," Bell Syst. Tech. J., Vol. 45, pp. 1775-1796, (1966).

[20] R.R. Mosier, and R.G. Clabaugh, "Kineplex, a bandwidth efficient binary transmission system," AIEE Trans. Vol. 76, pp. 723-728 (1958).

[21] H. Sanjoh, E. Yamada, Y Yoshikuni, "Optical orthogonal frequency division multiplexing using frequency/time domain filtering for high spectral efficiency up to $1 \mathrm{bit} / \mathrm{s} / \mathrm{Hz}$ ', Proc OFC'02, Anaheim, Paper ThD1, (2002)

[22] A. Sano, E. Yamada, H. Masuda, E. Yamazaki, T. Kobayashi, E. Yoshida, Y. Miyamoto, S. Matsuoka, R. Kudo, K. Ishihara, Y. Takatori, M. Mizoguchi, K. Okada, K. Hagimoto, H. Yamazaki, S. Kamei, and H. Ishii, "13.4-Tb/s (134 x 111-Gb/s/ch) No-Guard-Interval Coherent OFDM Transmission over 3,600 km of SMF with 19-ps average PMD", Proc ECOC'08, Brussels, Paper Th3E1 (2008).

[23] K. Takiguchi, M. Oguma, T. Shibata, H Takahashi, "Optical OFDM demultiplexer using silica PLC based optical FFT circuit", Proc OFC 2009, San Diego, Paper OWO3 (2009).

[24] A.D. Ellis, F.C.G. Gunning, "Filter strategies for coherent WDM", Proc. Emerging Technologies in Optical Sciences, 26th-29th July, Cork, 2004

[25] A.D. Ellis, F.C.G. Gunning, "Spectral Density Enhancement using Coherent WDM", Photonics Technology Letters, Vol. 17, No. 2, pp. 504-506, (2005)

[26] J. Zhao, A.D. Ellis, "Performance Improvement Using a Novel MAP Detector in Coherent WDM Systems", Proc ECOC'08, Paper Tu1.D.2, (2008).

[27] T. Healy, F.C. Garcia Gunning, E. Pincemin, B. Cuenot, A.D. Ellis, "1,200 km SMF (100 km spans) $280 \mathrm{Gbit} / \mathrm{s}$ Coherent WDM Transmission using Hybrid Raman/EDFA Amplification", ECOC'07, Berlin, paper Mo1.3.5 (2007).

[28] A.J. Lowery and J. Armstrong, "Orthogonal frequency division multiplexing for dispersion compensation of long-haul optical systems", Optics Express, Vol. 14, 2006, pp. 2079-2084 (2006).

[29] B.J.C. Schmidt, Z. Zan, L.B. Du, A.J. Lowery, "100 Gbit/s Transmission Using Single Band Direct Detection Optical OFDM", Proc OFC'09, San Diego, Paper PDPC4 (2009) 
[30] I.B. Djordjevic, B. Vasic, "100-Gb/s Transmission Using Orthogonal Frequency-Division Multiplexing", IEEE Photonics Technology Letters, Vol.18, No.15, pp. 1576-1578, (2006).

[31] S.L. Jansen, I. Morita and H. Tanaka, "10-Gb/s OFDM with conventional DFB lasers," in Proc. ECOC'07, Berlin Paper Tu. 2.5.2 (2007)

[32] W. Shieh "High Spectral Efficiency Coherent Optical OFDM for $1 \mathrm{~Tb} / \mathrm{s}$ Ethernet Transport", Proc OFC 2009, San Diego, Paper OWW1 (2009).

[33] S.L. Jansen, I. Morita, N. Takeda and H. Tanaka, "20-Gb/s OFDM Transmission over 4,160-km SSMF Enabled by RF-Pilot Tone Phase Noise Compensation," in Proc. Optical Fiber Communication (OFC) Conference 2007, Anaheim, Paper PDP 15 (2007).

[34] H. Takahashi, A. Al Amin, S.L. Jansen, I. Morita, H. Tanaka " DWDM Transmission with $7.0 \mathrm{bit} / \mathrm{s} / \mathrm{Hz}$ Spectral Efficiency Using 8x65.1 Gbit/s Coherent PDM OFDM Signals", in Proc OFC 2009, San Diego, Paper PDPB7 (2009).

[35] X. Yi, W. Shieh, Y. Ma, "Phase Noise on Coherent Optical OFDM Systems with 16-QAM and 64-QAM beyond $10 \mathrm{~Gb} / \mathrm{s}$ ", Proc ECOC'07, Berlin, Paper Tu5.2.3 (2007).

[36] T. Miki, H. Ishio, "Viabilities of the Wavelength-Division-Multiplexing Transmission System Over an Optical Fiber Cable", IEEE Transactions on Communications, Vol.26, No.7, pp. 1082-1087 (1978).

[37] A.D. Ellis, F.C.G. Gunning, B. Cuenot, T.C. Healy, E. Pincemin, M. Rukosueva, "Towards 1TbE using Coherent WDM", Proc OECC/ACOFT 2008, Sydney, Paper WeA-1 (2008).

[38] F.C. Garcia Gunning. T. Healy, X. Yang, A.D. Ellis, "0.6Tbit/s Capacity and $2 \mathrm{bit} / \mathrm{s} / \mathrm{Hz}$ Spectral Efficiency at $42.6 \mathrm{Gsymbol} / \mathrm{s}$ Using a Single DFB Laser with NRZ Coherent WDM and Polarisation Multiplexing", CLEO Europe 2007, Munich, Germany, paper CI8-5, (2007).

[39] Y. Ma, Q. Yang, Y. Tang, S. Chen, W. Shieh, "1 Tb/s per Channel Coherent Optical OFDM Transmission with Subwavelength Bandwidth Access", Proc OFC'09, San Diego, Paper PDPC1 (2009).

[40] J. Armstrong, "Peak-to-average power reduction for OFDM by repeated clipping and frequency domain filtering", Electronics Letters, Vol.38, No.5, pp. 246-248 (2002).

[41] D.J. Malyon, T. Widdowson, E.G. Bryant, S.F. Carter, J.V. Wright, W.A. Stallard, "Demonstration of optical pulse propagation over $10000 \mathrm{~km}$ of fibre using recirculating loop", Electronics Letters, Vol.27, No.2, pp120-121, (1991).

[42] H.J. Thiele, R.I. Killey, P. Bayvel, "Influence of fibre dispersion and bit rate on cross-phase-modulation-induced distortion in amplified optical fibre links", Electronics Letters, Vol.34, No.21, pp 2050-2051, (1998).

[43] A.D.Ellis, W.A.Stallard, "Four Wave mixing in ultra long transmission systems incorporating linear amplifiers", IEE Colloquium, No.159, (1990)

[44] R.-J. Essiambre, B. Mikkelsen, and G. Raybon, "Intra-channel crossphase modulation and four-wave mixing in high-speed TDM systems", Electronics Letters, Vol.35, No.18, pp. 1576-1578 (1999).

[45] A.D.Ellis, J.D. Cox, D. Bird, J. Regnault, J.V. Wright, W.A.Stallard, "5 Gbit/s soliton propagation over $350 \mathrm{~km}$ with large periodic dispersion coefficient perturbations using erbium doped fibre amplifier repeaters", Electronics Letters, Vol.27, No.10, pp. 878, (1991).

[46] I. Morita, K. Tanaka, N. Edagawa and M. Suzuki, "Impact of the dispersion map on long-haul 40 Gbith single-channel soliton transmission with periodic dispersion Compensation", Proc OFC'99, San Diego, Paper FD1, (1999).

[47] P.V. Mamyshev and L.F. Mollenauer, "Pseudo-phase-matched four-wave mixing in soliton wavelength-division multiplexing transmission", Optics Letters, Vol. 21, Issue 6, pp. 396-398 (1996).

[48] N.J.Smith, N.J. Doran, "Modulational instabilities in fibers with periodic dispersion management", Opt. Lett. Vol. 21, No. 8, pp. 570-572, April 1996.

[49] E Pincemin, A. Tan, A. Bezard, A. Tonello, S. Wabnitz, J-D AniaCastañòn, S. Turitsyn., "Robustness of $40 \mathrm{~Gb} / \mathrm{s}$ ASK modulation formats in the practical system infrastructure", Optics Express, Vol.14, No.25, pp1204912062, (2006).

[50] P.P.Mitra, J.B.Stark, "Nonlinear limits to the information capacity of optical fibre communications", Nature, Vol.411, pp 1027-1030, (2001).

[51] L.G.L. Wegener, b, M.L. Povinelli, A.G. Green, P.P. Mitra, J.B. Stark and P.B. Littlewood, "The effect of propagation nonlinearities on the information capacity of WDM optical fiber systems: cross-phase modulation and four-wave mixing", Physica D: Nonlinear Phenomena, Vol.189, No.1-2, pp. 81-99, (2004).
[52] R.J. Essiambre, G.J. Foschini, P.J. Winzer, G. Kramer, "Exploring capacity limits of fibre-optic mommunication systems", Proc ECOC 2008, Brussels, Paper We1E1, (2008).

[53] A.D. Ellis, S.J. Pycock, D.A. Cleland, C.H.F. Sturrock, "Dispersion compensation in a $450 \mathrm{~km}$ transmission system employing standard fibre", Elect Lett, Vol.28, No.10, pp 954, (1992).

[54] D. McGhan, C. Laperle, A. Savehenko, L. Chuandong, G. Mak, M. O'Sullivan, "5120 km RZ-DPSK transmission over G652 fiber at $10 \mathrm{~Gb} / \mathrm{s}$ with no optical dispersion compensation", Proc. OFC 2005, Anaheim , paper PDP27, (2005).

[55] J.H. Winters, R.D. Gitlin, "Electronic Signal Processing Techniques in Long Haul Fiber Optic Systems", IEEE Transactions on Communications, Vol.38. N0.9, pp. 1439-1453, (1990).

[56] M.E. McCarthy, J. Zhao, A.D. Ellis, P. Gunning, "Full-Field Electronic Dispersion Compensation of 10Gbit/s OOK without Raman Amplification over $4 \times 124 \mathrm{~km}$ Field-Installed SSF", Submitted to Journal of Lightwave Technology.

[57] M.G. Taylor, "Coherent detection method using DSP for demodulation of signal and subsequent equalization of propagation impairments", Photonics Technology Letters, Vol.16, No.2, pp. $674-676$ (2004).

[58] X. Liu, X. Wei, R.E. Slusher, C.J. McKinstrie, "Improving Transmission Performance in Differnetioal Phase-shift-keyed Systems by use of Lumped Nonlinear Phase-shift Compensation", Optics Letters, Vol.27, pp. 1616$1618,(2002)$

[59] K.Kikuchi, "Electronic Post-compensation for Nonlinear Phase Fluctuations in a 1000-km 20-Gbit/s Optical Quadrature Phase-shift Keying Transmission System Using the Digital Coherent Receiver", Optics Express, Vol.16, No.2, pp. 889-896, (2008).

[60] L. F. Mollenauer, A. Grant, X. Liu, X. Wei, C. Xie, I. Kang, C. Doerr, "Demonstration of 109 X 10G dense WDM over more than 18,000 km using novel, periodic-group-delay complemented dispersion compensation and dispersion managed solitons", Proc ECOC 03, Rimini, Post-deadline Paper Th4.3.4 (2003).

[61] C. Xu, X. Liu, X. Wei, "Differential Phase-Shift Keying for High Spectral Efficiency Optical Transmissions", IEEE Journal of Selected Topics in Quantum Electronics, Vol.10, No.2, pp. 281-293, (2004).

[62] W. Pieper, C. Kurtze, R. Schnabel, D. Bruer, R. Ludwig, K. Petermann, "Nonlinearity insensitive standard fibre transmission based on optical phase conjugation in a semiconductor amplifier", Electronics Letters, Vol.30, No.9, pp. 724-725, (1992).

[63] S. Watanabe, M. Shirasaki, "Exact Compensation for both Chromatic Dispersion and Kerr Effect in a Transmission Fiber Using Optical Phase Conjugation", Journal of Lightwave Technology, Vol.14, No.3, pp. 243-248, (1996).

[64] K. Roberts Chuandong Li L. Strawczynski M. O'Sullivan I. Hardcastle, "Electronic precompensation of optical nonlinearity", Photonics Technology Letters, Vol.18, No.2, pp 403-405, (2006).

[65] J.B. Stark, P.P. Mitra, A. Sengupta., "Information capacity for optical communication channels", Opt.Fiber Technol., Vol.7 pp275- (2001)

[66] B. Wu, E. Narimanov, "Information capacity of nonlinear fiber-optical systems", in Proc 2005 Quantum Electronics and Laser Science Conference (QELS), Paper JThE74, (2005).

[67] A. Mecozzi, M. Shtaif, "On the capacity of intensity modulated systems using optical amplifiers", Photonics Technology Letters, Vol.13, pp.10291031, (2001).

[68] R.-J. Essiambre, G.J. Foschini, P.J. Winzer, G. Kramer, E.C. Burrows, "The capacity of fiber-optic communication systems", Proc OFC2008, San Diego, paper OTuE1 (2008).

[69] H. Goto, M. Yoshida, T. Omiya, K. Kasai, M. Nakazawa, "Polarisation and frequency division multiplexed $1 \mathrm{Gsymbol} / \mathrm{s}, 64$ QAM coherent optical transmission with $8.6 \mathrm{~b} / \mathrm{s} / \mathrm{Hz}$ spectral efficiency over $160 \mathrm{~km}$ ", IEICE Electronics Express, Vol.5, No.18, pp. 776-781 (2008).

[70] S.L. Jansen, D. van den Borne, C. Climent, M, Serbay, C.-J. Weiske, H. Suche, P.M . Krummrich, S. Spalter, S. Calabro, N. Hecker-Denschlag, P. Leisching, W. Rosenkranz, W. Sohler, G.D. Khoe, T. Koonen, H. de Waardt, "10,200km 22x2x10Gbit/s RZ-DQPSK Dense WDM Transmission without Inline Dispersion Compensation through Optical Phase Conjugation", Proc OFC'05, Anaheim, Paper PDP28, (2005).

[71] L. Becouarn, G. Vareille, P. Pecci, J.F. Marcerou, "3Tbit/s Transmission (301 DPSK channels at $10.709 \mathrm{~Gb} / \mathrm{s}$ ) over $10270 \mathrm{~km}$ with a record efficiency of $0.65(\mathrm{bit} / \mathrm{s}) / \mathrm{Hz}$ " Proc ECOC 03, Rimini, Post-deadline Paper Th4.3.2 (2003). 
[72] Y.Kodama, S.Wabnitz, "Reduction of Soliton interaction forces by bandwidth limited amplification", Electronics Letters, Vol.27, No.21, pp1931-1932 (1991).

[73] J. Zhao, A.D. Ellis, F.C.G. Gunning, P. Frascella, S.K. Ibrahim, R. Weerasuriya, "High-Capacity Transmission Using Coherent WDM (Invited)", OECC 2009, Hong Kong, (2009).

[74] M. Seimetz, L. Molle, D.-D. Gross, B. Auth, R. Freund, "Coherent RZ8PSK Transmission at $30 \mathrm{Gbit} / \mathrm{s}$ over $1200 \mathrm{~km}$ Employing Homodyne Detection with Digital Carrier Phase Estimation", Proc ECOC'07, Berlin, Paper We8.3.4 (2007).

[75] A. H. Gnauck, G. Charlet, P. Tran, P. Winzer, C. Doerr, J. Centanni, E. Burrows, T. Kawanishi, T. Sakamoto, and K. Higuma, " 25.6-Tb/s C+L-Band Transmission of Polarization-Multiplexed RZ-DQPSK Signals," Proc OFC 2007, Anaheim, Paper PDP19, (2007).

[76] M. Yoshida, H. Goto, K. Kasai, and M. Nakazawa, "64 and 128 coherent QAM optical transmission over $150 \mathrm{~km}$ using frequency-stabilized laser and heterodyne PLL detection," Opt. Express Vol.16, pp. 829-840 (2008).

[77] I. Morita, N. Edagawa, "50GHz-Spaced 64 x 42.7 Gbit/s Transmission over $8200 \mathrm{~km}$ Using Pre-Filtered CS-RZ DPSK Signal and EDFA Repeaters", Proc ECOC'03, Rimini, Paper Th4.3.1 (2003).

[78] A.J. Lowery, "Fiber nonlinearity pre- and post-compensation for longhaul optical links using OFDM," Optics Express Vol.15 No.20 pp. 12965 (2007).

[79] E. Yamazaki , F. Inuzuka , K. Yonenaga , A. Takada and M. Koga "Compensation of interchannel crosstalk induced by optical fiber nonlinearity in carrier phase-locked WDM system," IEEE Photon. Technology Letters, Vol.19, pp. 9, (2007).

[80] L. Thylen, E. Berglind, O. Nilsson, "Channel capacity of optical fibres", Private communication (2002).

[81] H.A. Haus, Y. Yamamoto, "Quantum circuit theory of phase sensitive linear systems", IEEE Journal of Quantum Electronics, Vol.QE-23, pp. 212221, (1987).

[82] S. Oda, H. Sunnerud, P.A. Andrekson, "High efficiency and high output power fiber-optic parametric amplifier", Optics Letters, Vol. 32, No.13, pp. 1776-1778 (2007).

[83] G. Charlet, M. Salsi, H. Mardoyan, P. Tran, J. Renaudier, S. Bigo, M. Astruc, P. Sillard, L. Provost, F. Cérou, "Transmission of 81 channels at 40Gbit/s over a Transpacific-Distance Erbium-only Link, using PDM-BPSK Modulation, Coherent Detection, and a new large effective area fibre.", Proc ECOC'08, Brussels, Paper Th3E3 (2008).

[84] J.M.C. Boggio, C. Lundström, J. Yang, H. Sunnerud, P.A. Andrekson, "Double-pumped FOPA with $40 \mathrm{~dB}$ flat gain over $81 \mathrm{~nm}$ bandwidth", Proc ECOC 2008, Brussels, Paper Tu.3B5 (2008)

[85] P.J. Roberts, F. Couny, H. Sabert, B. Mangan, D. Williams, L. Farr, M. Mason, A. Tomlinson, T. Birks, J. Knight, and P. St. J. Russell, "Ultimate low loss of hollow-core photonic crystal fibres," Optics Express Vol.13, pp. 236244 (2005).

[86] K. Tajima, J. Zhou, K. Nakajima, and K. Kurokawa, "Ultra low loss and long length photonic crystal fiber”, Proc OFC'04, Los Angeles, Paper WI7 (2004).

[87] RM Percival, D Szebesta, CP Seltzer, SD Perin, ST Devey, M. Louka, "A 1.6- $\mu \mathrm{m}$ pumped 1.9- $\mu \mathrm{m}$ thulium-doped fluoride fiber laser and amplifier of very high efficiency", Journal of Quantum Electronics, Vol.31, No.3, pp. 489-493 (1995).

[88] A. Krier and Y. Mao, "High performance uncooled InAsSbP/InGaAs photodiodes for the 1.8-3.4 $\mu \mathrm{m}$ wavelength range", Infrared Physics \& Technology, Vol.38, No.7, pp. $397-403$ (1997).

[89] Z. Tong, Q. Yang, Y. Ma, W. Shieh, " 21.4 Gb/s Coherent Optical OFDM Transmission over $200 \mathrm{~km}$ Multimode Fiber", Proc OECC/ACOFT 2008, Syndey, Paper PDP5 (2008).

[90] M Bigot-Astruc, F Gooijer, N Montaigne, P Sillard, "Trench-Assisted Profiles for Large-Effective-Area Single-Mode Fibers", Proc ECOC'08, Brussels, Paper Mo.4.B1, (2008).

[91] C. Rasmussen, T. Fjelde, J. Bennike, L. Fenghai, S. Dey, B. Mikkelsen, P. Mamyshev, P. Serbe, P. van der Wagt, Y. Akasaka, D. Harris, D. Gapontsev, V. Ivshin, P. Reeves-Hall, "DWDM 40G transmission over transpacific distance $(10000 \mathrm{~km})$ using CSRZ-DPSK, enhanced FEC, and allRaman-amplified 100-km UltraWave fiber spans", Journal of Lightwave Technology, Vol.21, No.1, pp. 203-207, (2004).

[92] S. Ten, "Advanced Fibers for Submarine and Long-Haul Applications", in Proc. LEOS 2004, San Francisco, paper WJ2 (Vol. 2, pp. 543-544). 